\title{
Research on personal carbon consumption externalities and Its governance
}

\author{
Yin Long \\ Harbin University of Commerce, Harbin, China \\ yin_long@126.com
}

Keywords: carbon consumption externality governance

\begin{abstract}
Reducing carbon emissions, low-carbon life has now become a global consensus. China is not only a major producer of products, but also a major consumer of consumption. Individual citizens often unconsciously in daily consumption show a "high carbon" style. At present, people have not formed a high degree understanding of low-carbon consumption, that not only requires the government to strengthen propaganda to guide carbon consumption habits, but also needs scholars to find out the effective way to control personal carbon consumption, through analyzing economics principle of individual carbon consumption behavior. This paper adopts the microeconomics analysis method, establishes individual carbon consumption utility model, analyzes the reasons of the carbon consumption externalities' existence and its influence on society, and on this basis explores measures to govern the personal carbon consumption externalities.
\end{abstract}

\section{Introduction}

Today's civilization of human societies is inseparable from energy consumption, especially the consumption of fossil fuels, we can say that they are the foundation of modern civilization. Fossil energy consumption will produce large amounts of carbon dioxide, which would have been beneficial, forests and other plant need it for photosynthesis, carbohydrates human life needed also need it. But when carbon dioxide in the air exceeds a certain level, there will be a negative impact on the human survival environment, and now, global carbon dioxide emissions from heavy use of coal and oil have exceeded the capacity of the environment, leading to global warming and climate change.

The main cause of global warming is excessive carbon dioxide emissions of human nature. Climate change will lead a serious impact on human survival, hinder economic and social progress. Climate warming will bring rising sea levels, desertification of arable land, part of biological species extinction and other disasters. Reducing carbon emissions and stoping global warming have become the world's most important environmental problems.

Governments have also been concerned about global climate change, and take action to make policies. China as the world's largest developing country, in an effort to develop economy, at the same time, has been committed to protect the global environment through a variety of means in recent years, and decides to follow low-carbon economy development model. Low carbon economic model is a kind of low energy consumption, low emissions, low pollution as the foundation, high energy-efficient, high efficiency, high benefit as means, low carbon development as direction, energy conservation and emissions reduction and improve technology as approach. This is a global revolution in the mode of production, way of life, values and national rights and interests. Therefore, low-carbon economy is not only to change the traditional mode of production, but also to change people's current consumption patterns into low-carbon style.

China is not only a production power, and power consumption. Individual citizens in their daily consumption often unconsciously show "high carbon", such as housing the bigger ones, rarely consider the energy consumption; travelers rarely use public transport; use excessive plastic bags and other convenient consumption; use high energy consuming appliances and other high energy consuming; and there is also blind competition in consumption. Individuals have not yet formed a high degree of understanding to low carbon consumption, which not only need the government to 
strengthen propaganda to guide carbon consumption habits, to establish a "low carbon" morality, but also need scholars to find out the inherent law between individual carbon consumption behavior and "low carbon economy", through analyzing behavior economics principle of individual carbon consumption, to provide the impetus for sustainable economic development

\section{Consumption externality theory}

"All economic problems are externalities, some problem of externalities were already solved, some are being solved." Externality theory put forward can be traced back to Adam Smith, Smith said: "When one pursuits his own iterest, often promotes social interest", It is generally believed that the theory was systematically proposed by Marshall(1890), he used the concept of "external economy" when analyzing the organization. The concept of externality in the modern sense was first used by Pigou (1920), he systematically studied the problem of externality from the perspective of welfare economics.

Consumption affects the environment, but consumers do not pay the price for this external influence or obtain monetary benefits. For example, in the consumption of low-cost gasoline, consumers do not pay the price for carbon dioxide and other negative effects on the environment and others, we say this is a negative externality consumption. Consumption externalities exist widely, according to the nature of the externality, combined with the characteristics of consumption, we can give a definition of consumption externalities: the consumption behaviors of economic agents create an impact to others or the society, but economic agents have not obtain corresponding reward or give corresponding compensation. This paper mainly refers to the negative externalities of consumption.

Consumption externality theory analysis. When there is individual consumption with negative externalities in economy, since the private marginal cost is lower than the social marginal cost, so consumers tend to be over-consumption, over the optimal configuration. As shown in the figure 1, MSC is marginal social costs, MPC is private marginal costs, MSR is social marginal benefits (assuming private marginal revenue equals social marginal revenue). When there are no externalities, achieving equilibrium at $E_{1}$ point, consumption quantity is $Q_{1}$. In the presence of external costs, considering the private marginal cost is equal to the marginal revenue of private, individuals increase their consumption to $Q_{0}$, obviously there is excessive consumption. Then the actual cost of consumer is area of $o Q_{0} E_{0} P_{0}$, and social cost is area of $o Q_{0} A P_{1}$, external cost is the difference between the two, is area of $P_{0} E_{0} A P_{1}$, which is the amount of negative externalities resulting from the consumption.

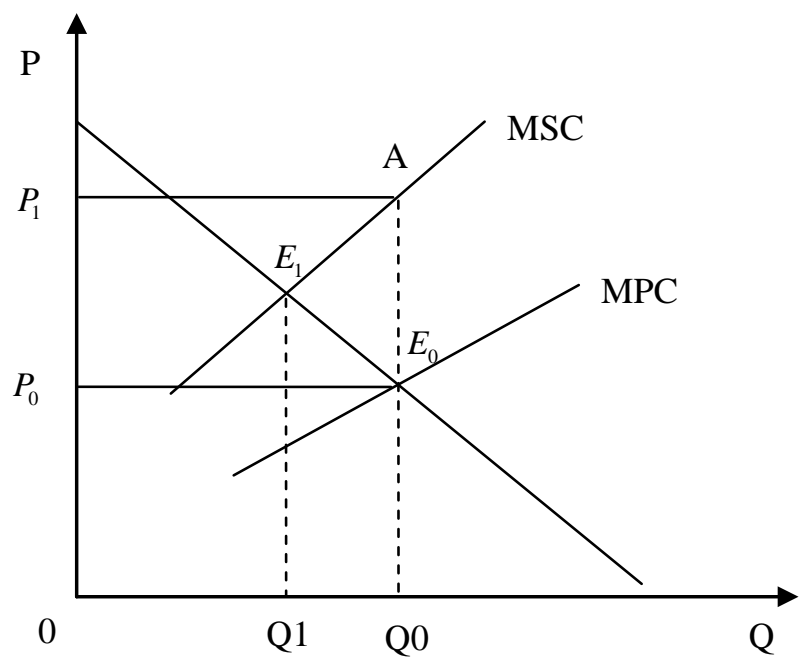

Fig. 1 Consumption externality theory analysis 


\section{Individual carbon consumption utility model}

In order to study the externality of personal carbon consumption, first of all, study the ordinary consumption, establish personal consumption standard utility function, on the basis of this function, considering carbon emissions in the personal consumption, obtain personal carbon consumption utility function.

$$
U=u\left(x_{1}, x_{2}, x_{3}, \ldots, x_{n}\right)
$$

Where $x_{i}$ is the number of consumer goods, this is standard utility function.

Now analyze individual carbon consumption utility, it is assumed that consumers know carbon emissions quantity of every goods. Individual carbon consumption mainly comes from the carbon emissions in the process of producing daily necessities and the direct energy consumption. According to its form and different sources, energy is divided into high-carbon energy and low-carbon energy. High carbon energy means that energy in the production and use with high carbon emissions, such as coal, oil, etc; low carbon energy means that energy in the production and use with low carbon emissions, such as wind power, solar energy, etc. Thus, we can get personal carbon consumption function.

$$
U=u\left(X_{h}, X_{l}, X_{n}\right)
$$

Where $X_{h}$ means high carbon energy, $X_{l}$ means low carbon energy, $X_{n}$ means daily necessities.

\section{Excessive carbon consumption externalities analysis}

The influence of excessive carbon consumption on production function. Human discharge carbon to the natural world in their production and consumption, if carbon emissions is not more than the adjustment ability of nature, we can not consider the impact, but if carbon emissions is beyond the adjustment ability of nature, it will cause damage to the environment, which will reduce the speed of human society development. So we must pay more attention to it. So that the total amount of carbon in nature is $T c$, its influence coefficient on production is $\theta(T c)$, the production function is:

$$
Y=\theta(T c) F(K, L)
$$

Now we analyze the total carbon's influence coefficient $\theta(T c)$ on production, when the total amount of carbon in nature is less than the critical value $T c^{*}$, the natural ecological balance can be reached through self-regulation, it will not affect the production function, which does not need to spend money to control carbon emissions. But when the total amount of carbon in nature is greater than $T c^{*}$, the ecological environment will deteriorate sharply due to carbon emissions, we have to govern carbon emissions with some cost form output Y. What's worse, when the total amount of carbon in the natural world continues to increase, reaching $T c^{* *}\left(T c^{* *}>T c^{*}\right)$,there will be a serious impact on the production function, most of $\mathrm{Y}$ is took out to govern ecological environment. $T c^{*}$ is the starting point of carbon emissions have an impact on the production function, $T c^{* *}$ is the inflection point where we will lost most of output Y.

The impact of excessive carbon consumption on consumers. Carbon emissions in the production and consumption of consumer goods, increases the burden on the ecological environment, if atmospheric carbon emissions exceed a certain standard, it will cause environmental degradation. But in most cases, carbon consumers are not responsible for the pollution caused by carbon products, which will inevitably lead to a decline in other consumer utility level. On the other hand, negative externality caused by carbon emissions, leades to the marginal cost of production increase, companies will inevitably raise prices as compensation for rising costs, then this part of the loss will eventually turned to consumers, resulting in loss of consumer welfare. 


\section{Personal carbon consumption externalities governance}

Economic Governance personal carbon consumption externalities. If not considering the negative externality of carbon consumption, personal consumption in pursue the maximum utility, is bound to increase the amount of carbon emissions to the environment, otherwise if there is strict restrictions on carbon consumption, it will reduce the personal consumption utility. The usual practice is for the government to tax carbon consumption, the use of changes in tax rates to adjust the carbon emissions that can be levied directly from carbon emissions. In general, the price of consumer goods and their carbon emissions is not linear, namely the goods of higher commodity prices may not ones of higher carbon emissions, so if we only tax on price, not distinguishing the goods through carbon emissions, this practice is unfair. Some similar goods, in the low-carbon production process may have higher cost and be priced at higer level, if they are taxed according to the price only, that will certainly lead to the result of double taxation, and it will reduce the enthusiasm of enterprises to improve production methods, play a negative effect on low carbon production. We are talking about a carbon tax, which refers to carbon footprint of the goods in the production process. This tax may be levied in commodity production, but can also be imposed on consumption by consumers pay. Since the carbon tax is levied on the individual, it can be completely reflected in the unit price of the commodity.

Social Governance personal carbon consumption externalities. In general, the impact on consumer behavior is complex, not just price and income, these two major factors, but also includes a variety of social factors, consumer habits and ecological values have significant effect on individual carbon consumption. Changing people's spending habits or lifestyle, the government's tax policy enforcement is not possible, only needs to perform guide policy. A habit change path is to reduce the direct remuneration of habitual behavior. Ecological values advocate green consumption, requires people to consider environmental factors in the consumption activities. Under the ecological values of consumption, people to save, to reduce the energy consumption, reduce carbon emissions. But it is not asking people to lower the quality of life, just put an end to luxury and extravagance. With the progress of social civilization, cological values will be accepted by the people, and is bound to bring about changes in consumer behavior.

\section{Acknowledgements}

This work was financially supported by Ministry of Education of China (10YJA790203), and Graduate student innovation research project (YJSCX2015-349HSD).

\section{References}

[1] Coase, Property Rights and Institutional Changes [M], Shanghai People's Publishing House, 1995.

[2] Gary S. Becker, Economic analysis of human behavior [M], Shanghai People's Publishing House, 2008.

[3] Yu Haishan, Zhou Yayue, Consumption Externalities and its Social Welfare Effect [J], Business Studies, 2007(2).

[4] Tapiero, C.S., Energy consumption and environmentalpollution:A stochastic model. IMA Journal Of Management Mathematics, Vol.20, No.3, 2009.

[5] Yu Shubo, Gong Luning, Analysis of urban residents consumption Based on the externality theory [J], Macroeconomic Research, 2015(3).

[6] Sheng Hong, Sheng Hong Set [M], Heilongjiang people's publishing house, 1993. 